\title{
Association of maternal oral health with early childhood caries among rural areas of Punjab
}

\author{
ROHEEN SHAKEEL ${ }^{1}$, ALIYA ISHAQUE ${ }^{2}$, AAQIL MALIK ${ }^{3}$, SHAHZAD WAHEED QURESHI ${ }^{4}$, GULREZ AMIN ${ }^{5}$, FAISAL ALI \\ BALOCH $^{6}$, AMINA TARIQ 7 \\ ${ }^{1}$ Demonstrator, Department of physiology, Bolan medical University of health sciences, \\ ${ }^{2}$ Demonstrator, Department of physiology, Bolan medical University of health sciences, \\ ${ }^{3}$ Associate Professor of Prosthodontics, University College of Medicine and Dentistry, University of Lahore \\ ${ }^{4}$ Associate Professor of Oral and Maxillofacial surgery, University College of Medicine and Dentistry, University of Lahore, \\ ${ }^{5}$ Associate Professor of Bio-chemistry, University College of Medicine and Dentistry, University of Lahore, \\ ${ }^{6}$ Assistant Professor of Science of Dental Materials, Baqai Dental College, Baqai Medical University, Karachi \\ ${ }^{7}$ Postgraduate research coordinator, Research cell, University College of Medicine and Dentistry, University of Lahore \\ Correspondence to Amna Tariq, Email id: aminatariq8@gmail.com Cell:0336-0333108
}

\begin{abstract}
Aim: To explore the relationship between oral health status of mothers and caries prevalence of caries among their children in rural areas of Pakistan.

Methodology: This crossectional study was conducted in 9 rural health centers of Punjab, Pakistan. Purposive convenient sampling was used to collect data. Sample size was 500 mothers with their children.

Results: Socioeconomic status of family as well as the purpose for the last visit at dental hospital for the treatment of child were found positively linked with the dmfs of child. Sample of children at very low socioeconomic status (OR: 2.16; 95\%Cl: 1.36-2.98). Children who visited dental hospital with the reason of having dental problems (OR: 1.89; $95 \% \mathrm{Cl}: 1.25-2.59)$. Greater dmfs score was found among children with poor oral hygiene $(\mathrm{OR}: 1.98 ; 95 \% \mathrm{Cl}$ : 1.27-3.25). The education of mother was found to be negatively linked with dmfs score of child.

Conclusion: The relationship between maternal and dental caries in children was clearly explained by socioeconomic status or dental behaviors of mother and child in terms of intake of sugar, oral hygiene and reason for last dental visit for child.
\end{abstract}

Keywords: Maternal oral health, dmfs, childhood carries

\section{INTRODUCTION}

Child development is based majorly on mothers as they take care for the growth and wellbeing of children. For the health improvement, mothers provide necessary assistance in terms of medical and emotional support ${ }^{1}$. Multiple factors may influence the health of children as well as their mothers, for instance, hereditary factors may include genetic factors, mental health issues ${ }^{2}$ and socio economic conditions of family.

Extensive research has been done on the effect of maternal health on early childhood caries ${ }^{3,4}$ which has led to explore the reason behind these childhood conditions ${ }^{5}$. This transfer mechanism showed that mothers are the main bacterial colonization source and socialization for their offspring. Acquiring healthy behaviors, dental services familiarity at earlier stage and ways of coping with stressors of life should be fostered by mothers ${ }^{3,5}$.

Although, oral health of parents reflects their frame of mind very well, which could influence their diet related choices and dental services usage, very limited literature is available which assessed the relationship between the oral health status of mother and prevalence of dental caries among children ${ }^{6}$. A study suggested that children between the age ranges from 2 to 6 years have more likely to develop dental caries if their mothers have untreated decayed tooth as well as tooth loss. ${ }^{7}$ Similar research investigation conducted by Pinto et al. suggested that dmfs score of children between the age of 2 years to 3.5 years

Received on 17-02-2021

Accepted on 27-06-2021 was linked with the prevalence of caries among mothers but gingival bleeding in mothers was not linked with dmfs score of child ${ }^{8}$. Prevalence of dental caries in children between the age of 11-12 years was positively associated to the maternal caries experience ${ }^{9}$, even if, in past year, the mothers have any active decay ${ }^{10}$. The literature on this association is limited and other maternal oral health factors need exploration.

The current study was designed to explore the relationship between oral health status of mothers and caries prevalence of caries among their children in rural areas of Pakistan.

\section{MATERIAL AND METHODS}

This cross sectional study was conducted in 9 rural health centers of Punjab, Pakistan. Purposive convenient sampling was used to collect data with permission from Ethical Committee. Sample size was 500 mothers with their children.

Inclusion criteria:

1. Age range between 2 years -6 years

2. Both genders

3. Patients with dental caries

Exclusion Criteria:

1. Children with comorbidities were excluded

2. Pregnant patients

Data Collection procedure: Questionnaire was used to collect data which was filled by mothers and for clinical data, examinations done for both mothers and their children. As demographic variables, questionnaire consisted of age, socioeconomic status and behavioral 
factors such as intake of sugars which were for mothers and for children, demographics were gender, age and their behavioral aspects such as intake of sugar and reason for visiting dentist. After explaining the research purpose and taking consent, mothers along with their children were clinically examined by the dentist. Dental caries and oral hygiene was examined in children as well as in mothers. Dental caries was examined using mirror and probe. Debris index was used to assess the oral hygiene which was taken from Oral Hygiene Index ${ }^{11}$ scored as 0-0.6 as good oral hygiene, 0.7 to 1.8 as fair oral hygiene and 1.9 to 3.0 as poor oral hygiene ${ }^{12}$.

Data analysis: Data analysis was performed in SPSS version 23.0. Multinomial regression analysis was used to explore the relationship between maternal oral hygiene and dental caries among children.

\section{RESULTS}

Sample size of this research study was 500 mothers and their children which were evaluated. Table1 showed the results of multinomial regression analysis. Majority of mothers' data showed that their age was less than 23years
(66.5\%), having primary school level education (58.7\%) with a low socioeconomic status (85.9\%). Nearly $90 \%$ mothers had dental caries. Additionally, the intake of sugarsweetened breakages once or more than once per day was found in $65.3 \%$ of mothers and $69.4 \%$ of children, whereas $40.6 \%$ mothers and $45.9 \%$ children was found to have poor status of oral hygiene in rural areas of Punjab, Pakistan. The mean value of $\mathrm{dmfs}$ was $8.3 \pm 8.3$ with only $30.9 \%$ of total sample of children were found at caries-free status. Decayed surface of tooth was the key element of the dmfs with the mean value of $4.3 \pm 4.5$.

Socioeconomic status of family as well as the purpose for the last visit at dental hospital for the treatment of child were found positively linked with the dmfs of child. Sample of children at very low socioeconomic status (OR: 2.16; 95\%Cl: 1.36-2.98). Children who visited dental hospital with the reason of having dental problems (OR: 1.89; 95\% $\mathrm{Cl}$ : 1.25-2.59). Greater dmfs score was found among children with poor oral hygiene (OR: 1.98 ; $95 \% \mathrm{Cl}$ : $1.27-$ 3.25). The education of mother was found to be negatively linked with dmfs score of child.

Table 1| Association of maternal oral health and dental caries in children

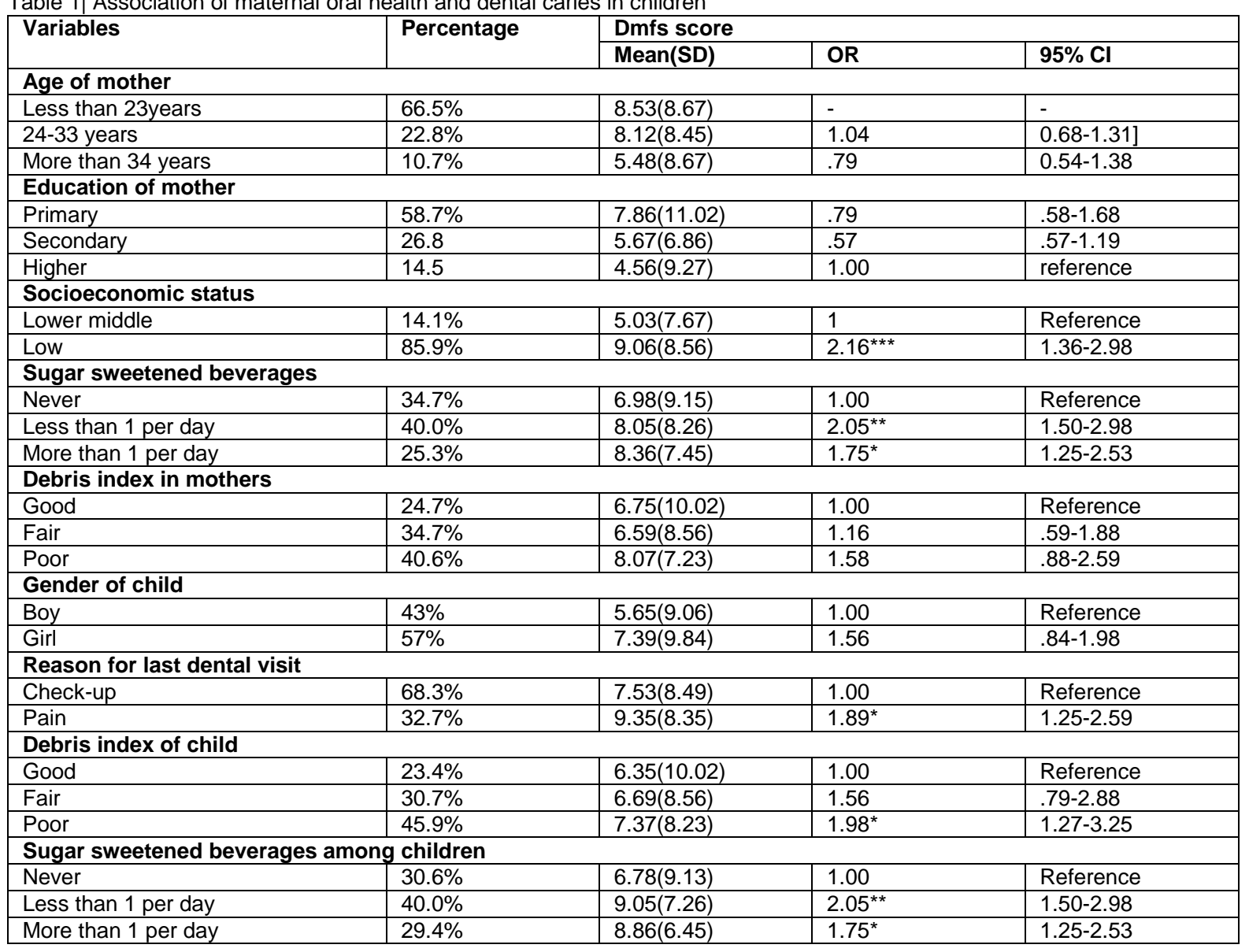




\section{DISCUSSION}

The current study explored the association between maternal dental caries prevalence associated with dental caries in children. This relationship was clearly explained by socioeconomic status or dental behaviors of mother and child in terms of intake of sugar, oral hygiene and reason for last dental visit for child.

The findings of this study showed that majority of mothers' data showed that their age was less than 23 years $(66.5 \%)$, having primary school level education (58.7\%) with a very low socioeconomic status (85.9\%). Nearly $90 \%$ mothers had dental caries. Additionally, the intake of sugarsweetened breakages once or more than once per day was found in $25.3 \%$ of mothers and $30.6 \%$ of children, whereas $40.6 \%$ mothers and $45.9 \%$ children was found to have poor status of oral hygiene in rural areas of Punjab, Pakistan. The mean value of $\mathrm{dmfs}$ was $8.3 \pm 8.3$ with only $30.9 \%$ of total sample of children were found at caries-free status. Decayed surface of tooth was the key element of the dmfs with the mean value of $4.3 \pm 4.5$.

Socioeconomic status of family as well as the purpose for the last visit at dental hospital for the treatment of child were found positively linked with the dmfs of child. Sample of children at very low socioeconomic status (OR: 3.00; 95\%Cl: 1.38-3.89). Children who visited dental hospital with the reason of having dental problems (OR: 2.57; 95\% Cl: 2.10-3.30). Greater dmfs score was found among children with poor oral hygiene (OR: 2.06 ; $95 \% \mathrm{Cl}: 1.20$ 3.65). The education of mother was found to be negatively linked with dmfs score of child. Children whose mothers have higher education showed low at dmfs score 35\% (OR: 1.61 ; $95 \% \mathrm{Cl}$ : $1.39-2.0)$ as compared to those children whose mothers education was at primary level. The findings of current study are in line with the study outcomes conducted on American children ${ }^{7}$ (Dye et al., 2011) as well as on Colombian population ${ }^{13}$

\section{CONCLUSION}

In conclusion, the relationship between maternal and dental caries in children was clearly explained by socioeconomic status or dental behaviors of mother and child in terms of intake of sugar, oral hygiene and reason for last dental visit for child.

Conflict of interest: Nil

\section{REFERENCES}

1. Al-Ayed, I.H. Mothers' knowledge of child health matters: Are we doing enough?. Journal of Family and Community Medicine, 2010, 17, 22-28.

2. Nolvi, S., Bridgett, D.J., Korja, R., Kataja, E.L., Junttila, N., Karlsson, H. Karlsson, L. Trajectories of maternal pre- and postnatal anxiety and depressive symptoms and infant fear: Moderation by infant sex. Journal of Affective Disorders, 2019. 257, 589-597.

3. Tinanoff, N., Baez, R.J., Diaz Guillory, C., Donly, K.J., Feldens, C.A., McGrath, C., Phantumvanit, P., Pitts, N.B., Seow, W.K., Sharkov, N., Songpaisan, Y., Twetman, S. Early childhood caries epidemiology, aetiology, risk assessment, societal burden, management, education, and policy: Global perspective. International Journal of Paediatric Dentistry, 2019, 29, 238-248.

4. Harris, R., Nicoll, A.D., Adair, P.M., Pine, C.M. Risk factors for dental caries in young children: A systematic review of the literature. Community Dental Health, 2009 21, 71-85.

5. Kim Seow, W. Environmental, maternal, and child factors which contribute to early childhood caries: A unifying conceptual model. International Journal of Paediatric Dentistry 2012, 22,157-168

6. Hooley, M., Skouteris, H., Boganin, C., Satur, J., Kilpatrick, N. Parental influence and the development of dental caries in children aged 0-6 years: A systematic review of the literature. Journal of Dentistry, 2012, 40, 873-885.

7. Dye, B.A., Vargas, C.M., Lee, J.J., Magder, L., Tinanoff, N. Assessing the relationship between children's oral health status and that of their mothers. Journal of the American Dental Association, 2011, 142, 173-183

8. Pinto, G.D.S., Azevedo, M.S., Goettems, M.L., Correa, M.B., Pinheiro, R.T., and Demarco F.F. Are maternal factors predictors for early childhood caries? Results from a cohort in Southern Brazil. Brazilian Dental Journal, 2017, 28, 391-397.

9. Nourijelyani, K., Yekaninejad, M.S., Eshraghian, M.R., Mohammad, K., Rahimi Foroushani, A., Pakpour A. The influence of mothers' lifestyle and health behavior on their children: An exploration for oral health. Iran Red Crescent Medical Journal, 2014, 16, e16051

10. Laniado, N., Shah, P., Moss, K.L., Badner, V.M. Mother's caries experience as a risk factor for child's oral health: An analysis of a high-risk population in the Bronx, New York. Pediatric Dentistry, 2019, 41, 279-284.

11. Green, J.C., Vermillion, J.R. The simplified oral hygiene index. Journal of the American Dental Association, 1964, 68, 7-13.

12. Green, J.C. The Oral Hygiene Index--development and uses. Journal of Periodontology, 1967, 38, 625-637.

13. Mafla AC, Moran LS, Bernabe E. Maternal Oral Health and Early Childhood Caries amongst Low-Income Families. Community Dent Health. 2020 Aug 31;37(3):223-228. doi: 10.1922/CDH_00040Mafla06. PMID: 32227706. 